\title{
Characterization of Heat Protective Aerogel-Enhanced Textile Packages
}

\author{
Sylwia Krzemińska ${ }^{1 *}$, Agnieszka Greszta $^{1}$, Pamela Miśkiewicz ${ }^{2}$ \\ ${ }^{1}$ Central Institute for Labour Protection - National Research Institute, Department of Personal Protective Equipment, \\ Czerniakowska 16, Warsaw 00-701, Poland \\ ${ }^{2}$ Institute of Architecture of Textiles, Faculty of Material Technologies and Textile Design, Lodz University of Technology, \\ 116 Zeromskiego St., Lodz 90-924, Poland
}

\section{Corresponding Author Email: sykrz@ ciop.lodz.pl}

https://doi.org/10.18280/ijht.380310

Received: 15 June 2020

Accepted: 3 Spetember 2020

\section{Keywords:}

aerogel, employee protection in the work environment, exposure to contact heat, exposure to convective heat, exposure to radiant heat, thermal conductivity, thermal resistance, insulating package, protective clothing

\begin{abstract}
The aim of this study was to investigate the effects of aerogel application on the thermal properties of textile packages intended for use in protective clothing. The packages were prepared in the form of removable inserts filled with aerogel, differing in terms of fabric and design. The developed packages were tested for resistance to the three major types of heat: radiant, convective, and contact. The package variant with superior thermal performance was also evaluated for water vapor resistance. The package after incorporation of aerogel was found to approximately double radiant and convective heat resistance, with an approx. eightfold improvement for contact heat at the highest test temperature $250^{\circ} \mathrm{C}$. Threshold time increased from $(17.7 \pm 0.7) \mathrm{s}$ to $(139.9 \pm 4.9) \mathrm{s}$ for the optimum aerogel-enhanced package variant with the greatest number of pouches, which met the criteria of the highest performance level. The thermal conductivity and thermal resistance of three fabrics selected for testing were tested in order to determine their basic thermal insulation properties. In general, packages containing a larger number of narrower pouches exhibited higher thermal protective performance. The results show that the developed textile packages with aerogel can be successfully used in thermal protective clothing.
\end{abstract}

\section{INTRODUCTION}

The discovery of aerogels in the 1930s was a major breakthrough in the development of novel ultralight materials with a wide application potential. Indeed, aerogels still remain the subject of intensive scientific research. According to the International Union of Pure and Applied Chemistry (IUPAC), aerogels are defined as gels consisting of a microporous solid in which the dispersed phase is the gas [1]. They are the lightest known solids with a density ranging from $0.003 \mathrm{~g} / \mathrm{cm}^{3}$ to $0.5 \mathrm{~g} / \mathrm{cm}^{3}[2,3]$, which comes close to the specific density of air $\left(0.0013 \mathrm{~g} / \mathrm{cm}^{3}\right)$. At the same time, aerogels exhibit very high porosity (up to $99.8 \%$ ) and specific surface area (500$\left.1000 \mathrm{~m}^{2} / \mathrm{g}\right)$, as well as extremely low thermal conductivity $(0.005-0.015 \mathrm{~W} / \mathrm{mK})[4,5]$. Due to this combination of unique properties, they are widely used for thermal insulation (e.g., in the construction, clothing, and refrigeration industries), acoustic insulation, adsorption, filtration, and for numerous other purposes [6-8]. The numerical simulations conducted by Saio et al. [9] showed that aerogel insulation applied to the external walls of buildings may reduce demand for heating by approx. $40 \%$ as compared to only $25 \%$ for traditional insulation.

The excellent insulation properties of aerogels are attributable to very low thermal conductivity, which is in turn associated with their extensive microporous internal structure [10]. Other important features that make aerogels particularly suitable for insulation applications are their extremely low weight as well as hydrophobicity, due to which they do not absorb moisture (as it has been shown for, e.g., silica aerogels) [11]. These unique properties have prompted a substantial body of research into aerogel applications, including in clothing materials to enhance their insulation parameters [1217]. Silica aerogel is the most common type of aerogel, with aluminum, carbon, titanium oxide, and zinc aerogels being much less popular [18]. Luo and Wang [19] improved the flame retardancy and thermal insulation properties of a cellulose aerogel by $\mathrm{TiO}_{2}$ doping and modification. The obtained $\mathrm{TiO}_{2}$-modified cellulose nanocrystal (CNC) composite aerogels exhibited a higher thermal decomposition temperature $\left(239^{\circ} \mathrm{C}\right)$ than unmodified $\mathrm{CNC}$ aerogel $\left(213^{\circ} \mathrm{C}\right)$. As compared to conventional insulators, aerogel-containing materials are characterized by higher resistance to heat with thermal insulation capacity being two to six times greater due to their structural properties [10].

Much of recent research has focused on aerogel implementations in textile materials with a view to improving their resistance to high temperatures. Most studies in this field have investigated composites made of silica aerogel and aramid [20-22], glass [23, 24], and polyester [25] nonwovens, or nonwovens combining different types of fibers [17, 26]. Such materials can be generally produced in three ways. First, aerogel particles may be added into the nonwoven fibrous web before bonding of the fibers [27]. The second method involves treating a finished nonwoven with an aerogel dispersed in a solvent, e.g., acetone [12]. Third, composites may be fabricated by immersing the nonwoven into a sol-gel solution [28]. Due to the inherent brittleness of aerogels and their 
unfavorable propensity to generate dust, nonwoven composites with aerogel are often laminated, e.g., with thin membranes [12, 29]. To prevent dust formation, Rahman Bhuiyan et al. [17] presented a layered aerogel-enhanced material made by spraying aerogel on a viscose-polyester nonwoven, which was then covered with another nonwoven layer and thermally bonded in a stream press. Prevolink et al. [29] developed a five-layer material in which the commercially available aerogel composite Spaceloft (Aspen Aerogels, Inc.) was laminated with a breathable membrane and a warp-knitted fabric on both sides. In turn, Ahmed et al. [30] produced a thermally resistant nonwoven material using a dust-free alginate aerogel. Finally, Shaid et al. [14] designed a hybrid thermal liner with the outer side being coated with silica aerogel particles and the inner side modified with a combination of aerogel and a phase change material.

The literature also provides some examples of aerogel applications in woven fabrics. For instance, Shaid et al. [13] developed a wool-aramid blended fabric coated with an acrylic binder and silica aerogel for protective clothing to improve the thermo $\neg$ physiological comfort of firefighters. In turn, Jabbari et al. [31] coated a polyester woven fabric with a mixture of silica aerogel and poly (vinyl chloride) using knife coating method. Venkataraman et al. [32] obtained a material exhibiting effective thermal resistance to laser radiation by embedding aerogel between glass and Kevlar fabrics. Another interesting solution involved aluminum hydroxide aerogel/polysulfonamide fabric composites offering protection against high temperature and flames [15]. The thermal conductivity of the composite was beneficially reduced with respect to the original polysulfonamide material, from 0.0513 to $0.0301 \mathrm{~W} /(\mathrm{m} \cdot \mathrm{K})$. Miśkiewicz et al. [33] applied aerogels on the surface of a basalt fabric to improve the thermal properties of protective gloves upon exposure to, e.g., contact and radiant heat. In a recent study, Bhuiyan et al. [34] developed an innovative cotton fabric coated with polyurethane and silica aerogel particles, that provided protection against chemicals and at the same time guaranteed improved thermal comfort.

A number of published studies have also investigated textile packages containing aerogel. Sindall et al. [35] developed a multi-layer sheet insulator in the form of a bonded assembly encapsulating aerogel to improve the thermal resistance of clothing. The insulator comprised of a fiber-reinforced aerogel composite laminated between plastic sheets, with the surfaces of the sheets and the aerogel composite having elongated depressions facilitating garment flexing. In turn, Seth et al. [36] patented an innovative method of manufacturing aerogel composites in which an aerogel monolith or a fiber-reinforced aerogel monolith was placed in cavities between a base layer and a structured layer that was bonded to the base layer. According to the patent description, the composite layers could be made from either textile materials or foams.

With the development of new aerogel-enhanced materials, it has become necessary to test them and evaluate their properties in terms of specific applications, e.g., in heat resistant protective clothing. In recent years many authors have addressed the resistance of textile materials with embedded aerogel to high temperatures and other heat factors. In a study on the impact of aerogel drying and aging on the thermal conductivity of glass wool-silica aerogel composites, Iswar et al. [24] found that insufficient aging led to aerogel shrinkage and cracking.

The resistance of aerogel-containing textile materials to thermal radiation has been explored among others by Qi et al. [20], Jin et al. [12], Chakraborty et al. [37, 38], Miśkiewicz et al. [33], and Bhuiyan et al. [34]. In their investigations of aerogel-enhanced firefighter's protective clothing (FPC), Qi et al. [20] found that upon exposure to an incident heat flux of $17.6 \mathrm{~kW} / \mathrm{m}^{2}$ for $860 \mathrm{~s}$ the temperature on the back surface of FPC samples filled with aerogel was by $100^{\circ} \mathrm{C}$ lower than that of unfilled samples. The application of aerogel not only improved insulation, but also decreased the weight of FPC by $24.3 \%$. In turn, Chakraborty et al. [37], who analyzed the resistance of aramid nonwovens with and without silica aerogel to radiant heat, recorded the time to crossing Stoll's curve for second-degree burn injury for samples subjected to a radiant heat flux of $35 \mathrm{~kW} / \mathrm{m}^{2}$. In subsequent studies, Chakraborty et al. [38] developed a novel type of aerogelenhanced nonwoven changing the precursor to methyltrimethoxysilane (MTMS) and increasing its concentrations compared to the previous one. The improved fabric assembly with aerogel showed a more than $100 \%$ increase in heat protection time during exposure to thermal radiation as compared to a conventional unimproved assembly. Enhanced resistance to radiant heat was also reported by Miśkiewicz et al. [33], who coated basalt fabrics with an aerogel-adhesive mixture. Furthermore, in experiments conducted by Bhuiyan et al. [17], the resistance of aerogelcontaining nonwovens to radiant heat increased with aerogel concentration. It was noticed that the nonwoven without the aerogel reached the pain threshold $\left(44^{\circ} \mathrm{C}\right)$ within $192 \mathrm{~s}$ of radiant heat exposure, whereas the maximum time (340 s) was recorded for the nonwoven with $4.0 \mathrm{~g}$ aerogel. The radiant heat resistance of textile materials with aerogel has been mostly investigated using cone calorimeters. Li et al. [39] and Huang et al. [21] reported that the fire hazard posed by aerogelincorporating composites decreased with increasing molar ratio of water to silica.

For textile materials to be used by firefighters and other personnel exposed to high temperatures, e.g., in steelworks and metallurgical plants, they should be able to resist not only radiant, but also convective heat. $\mathrm{Na}$ et al. [40] reported that silica aerogel improved the convective heat resistance of silica fabrics coated with silicone resins. Moreover, the addition of even small amounts of aerogel increased the flame retardancy of the materials. Jin et al. [12] analyzed the influence of aerogel embedded in the thermal insulation layer of firefighter clothing on its convective heat resistance using the copper calorimeter method described in the standard ISO 9151:2007 [41]. The studied meta-aramid nonwoven with aerogel exhibited superior thermal protective performance (TPP) as compared to an aramid layer without aerogel. During a flame heat transmission test at a heat flux density of $80 \mathrm{~kW} / \mathrm{m}^{2}$, the heat transfer index $\left(\mathrm{HTI}_{24}\right)$ increased in proportion to aerogel content in the nonwoven (from $0 \%$ to $70 \%$ ).

Only a few studies have been published to date on the resistance of textile materials with aerogel to contact heat. $\mathrm{Li}$ et al. [42] investigated heat transfer through aramid fiber reinforced aerogel composites upon contact with hot surfaces $\left(100^{\circ} \mathrm{C}, 200^{\circ} \mathrm{C}\right.$, and $\left.300^{\circ} \mathrm{C}\right)$. Similar experiments, but at a hot plate temperature of $60^{\circ} \mathrm{C}$ or $200^{\circ} \mathrm{C}$ under a compressive load of $49 \mathrm{~N}$, were conducted by Shaid et al. [22], who compared a nonwoven with aerogel with a commercially available thermal barrier implemented in firefighter clothing. Finally, Miśkiewicz et al. [33] investigated the resistance of a basalt fabric with an aerogel coating to contact heat generated by a $250^{\circ} \mathrm{C}$ cylinder according to the methodology specified in EN 
ISO 12127-1:2015 [43].

In summary, the properties of aerogels and aerogelenhanced materials such as nonwovens and composites have been widely discussed in the literature. Much less research has been devoted to the development and evaluation of woven fabrics incorporating aerogels, and in particular those applied in heat resistant clothing. Few studies have also investigated aerogel-containing textile packages designed for thermal protective materials. Indeed, there is a scarcity of data on the properties of such packages exposed to thermal factors, including those occurring in the work environment of firefighters and steel workers.

The aim of this work was to investigate the effects of aerogel application on the thermal properties of textile packages designed for protective clothing. Previous studies have focused on the evaluation of selected properties of aerogels and the possibility of incorporating them mainly in nonwovens and polymeric composites. In this paper, textile packages with hydrophobic silica aerogels were developed and tested in terms of their resistance to radiant, convective, and contact heat, which represent occupational hazards for workers in a number of industries. The findings were then compared to the performance requirements specified in protective clothing standards. Importantly, the presented textile package design involved sealed pouches filled with aerogel. The novel aspects of this study included the characterization of aerogel-enhanced textile packages and the determination of the effects of aerogel application on their heat insulation properties.

\section{MATERIALS}

\subsection{Aerogel}

Heat resistant packages were prepared using silica aerogel granules purchased from Cabot Co., USA (designated as CG). Figure 1 shows an image of the aerogel acquired with an Axiotech optical microscope (Carl Zeiss SMT Ltd., UK) with a Nikon DS-Fi1 digital camera and a Nikon DS-U2 controller (Nikon Corporation, Japan). Aerogel characteristics are given in Table $1[44,45]$.
Table 1. Aerogel specifications $[44,45]$

\begin{tabular}{cc}
\hline Parameter & Value \\
\hline Composition & {$[($ Trimethylsilyl)oxy]-modified silica } \\
Particle size range & $100-700 \mu \mathrm{m}$ \\
Pore diameter & $\sim 20 \mathrm{~nm}$ \\
Bulk density & $60-150 \mathrm{~kg} / \mathrm{m}^{3}$ \\
Surface chemistry & Hydrophobic \\
Thermal conductivity & $12 \cdot 10^{-3} \mathrm{~W} / \mathrm{mK}$ \\
BET surface area & $740.7 \mathrm{~m}^{2} / \mathrm{g}$ \\
Pore volume & $5.04 \mathrm{~cm}^{3} / \mathrm{g}$ \\
\hline
\end{tabular}

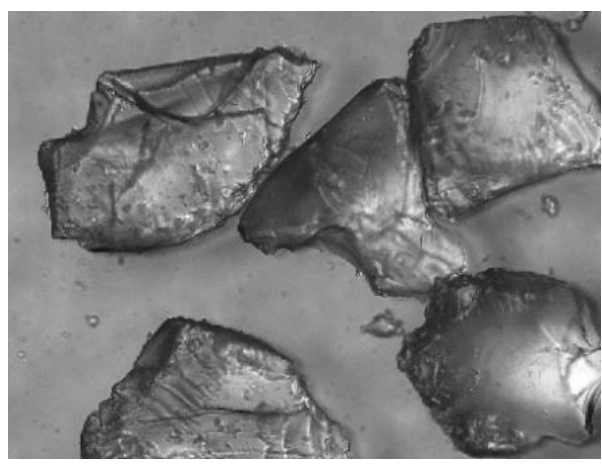

Figure 1. Optical microscope image of silica aerogel [44]

\subsection{Fabrics for package preparation}

Aerogel packages were prepared using aramid fabrics that differed in terms of coating. An aramid fabric (symbol a) with a polyurethane (PU) coating was purchased from Sofileta SAS (France), an aramid fabric (symbol b) with a teflon (PTFE) membrane was from Optex S.A. (Poland), and an aramid fabric (symbol c) with an acrylic-styrene dispersion coating was from P.P.H.U. Bochemia (Poland). The fabrics were characterized in Table 2. Fabrics a and $\mathrm{b}$ were characterized by a similar mass per unit area, much lower than for fabric $\mathrm{c}$ and similar tensile strength, also preferably much higher than for fabric c. All tested fabrics had high resistance to water penetration

Table 2. Characterization of textile materials

\begin{tabular}{|c|c|c|c|}
\hline Parameter & $\begin{array}{l}\text { Aramid fabric with } \\
\text { polyurethane coating } \\
\text { (a) }\end{array}$ & $\begin{array}{c}\text { Aramid fabric with Teflon } \\
\text { membrane } \\
\text { (b) }\end{array}$ & $\begin{array}{l}\text { Aramid fabric with acrylic-styrene } \\
\text { dispersion coating } \\
\text { (c) }\end{array}$ \\
\hline Composition & $\begin{array}{l}64 \% \text { Nomex } \\
36 \% \text { PU }\end{array}$ & $\begin{array}{c}97.5 \% \text { aramid } \\
2.5 \% \text { antistatic fiber }+ \text { Teflon } \\
\text { membrane }\end{array}$ & $\begin{array}{c}97.5 \% \text { aramid } \\
2.5 \% \text { antistatic fiber }+ \text { acrylic-styrene } \\
\text { layer }\end{array}$ \\
\hline Mass per unit area ${ }^{1}, \mathrm{~g} / \mathrm{m}^{2}$ & $207.1 \pm 0.3$ & $186.2 \pm 0.2$ & $314.7 \pm 26.4$ \\
\hline Thickness $^{2}, \mathrm{~mm}$ & $0.40 \pm 0.005$ & $0.35 \pm 0.00$ & $0.43 \pm 0.02$ \\
\hline Tensile strength $^{3}, \mathrm{~N}$ & $978 \pm 2$ & $919 \pm 23$ & $753 \pm 47$ \\
\hline $\begin{array}{c}\text { Resistance to water } \\
\text { penetration }^{4}, \mathrm{hPa}\end{array}$ & $<999$ & $<999$ & 650 \\
\hline \multicolumn{4}{|l|}{$\begin{array}{c}\text { Photograph } \\
\text { (optical microscope) }\end{array}$} \\
\hline & (magnification $\times$ 5) & (magnification x 5) & (magnification $\mathrm{x} 10$ ) \\
\hline
\end{tabular}

Notes:

1 - mass per unit area was determined according to EN ISO 2286-2:2016;

2- thickness was determined according to EN ISO 5084:1996;

3 - tensile strength was determined according to EN ISO 13934-1:2013;

4- resistance to water penetration was determined according to EN ISO 811:2018. 
The seams of package were sealed with heat-sealable tapes: a three-layer LT 3410 tape and a two-layer LS 390-110 tape, both with a width of $20 \mathrm{~mm}$, manufactured by Loxy (Sweden).

The first of the fabrics (fabric a) was commercially available. The next two fabrics (fabrics b and c) were specially prepared for the project using the same aramid textile and different types of coatings.

Preparation of coating for fabric b

Aramid fabric (97.5\% aramid / 2.5\% antistatic fiber, Andropol Poland) was laminated with a vapor-permeable and waterproof PTFE (polytetrafluoroethylene) membrane using a hot melt laminator. The temperature of the adhesive used was $90-100^{\circ} \mathrm{C}$. The lamination process was carried out at temperature $21^{\circ} \mathrm{C}$ and relative humidity $65 \%$.

Preparation of coating for fabric c

Aramid fabric (97.5\% aramid / 2.5\% antistatic fiber, Andropol Poland) was coated with acrylic-styrene dispersion.

The composition of the coating dispersion was as follows:

- acrylic-styrene glue - $85.0 \%$

- flame retardant, $45 \%$ ammonium polyphosphate solution in water $-13.8 \%$

- wetting agent, solution of more than $85 \%$ alcoxylated alcohols in water $-1.2 \%$.

Coating was carried out using the coating line using the following conditions:

- temperature at the beginning of the tunnel $83^{\circ} \mathrm{C}$,

- temperature at the end of the tunnel $100^{\circ} \mathrm{C}$,

- tunnel length $12 \mathrm{~m}$,
- set blade thickness $0.1 \mathrm{~cm}$,

- drying time $5 \mathrm{~min}$.

\subsection{Design of packages with aerogel}

Three types of packages with aerogel were developed, designated as $\mathrm{P} 1, \mathrm{P} 2$, and $\mathrm{P} 3$. The packages differed in terms of the number and width of pouches, as well as the width of overlaps covering the seams between pouches. Schematic diagrams, cross sections and photographs of the packages are presented in Table 3. Package P1 had six $25 \mathrm{~mm}$ wide pouches with $10 \mathrm{~mm}$ overlaps, P2 had seven $20 \mathrm{~mm}$ pouches with 8 $\mathrm{mm}$ overlaps, and P3 had ten $15 \mathrm{~mm}$ wide pouches with 10 mm overlaps.

All packages were made by sewing pouches onto a bottom layer using a DLN-5410-4 single-needle lockstitch machine (Juki Corporation, Japan). The pouches were attached in such a way that one seam secured the edges of the neighboring pouch. The pouch overlap differed in width between package types. Each pouch was filled with silica aerogel granules. The total weight of enclosed aerogel also differing between package types. To secure the granules in the pouches, the seams were sealed on the inside using a thin two-layer heatsealable tape. After inserting aerogel, the upper edges of the pouches were top-stitched and sealed with a three-layer heatsealable tape, which was also used to seal the other seams on the outside of the packages. The seams were sealed at $490^{\circ} \mathrm{C}$ using a Framis NS 500 machine (Framis Italia HK Ltd, Italy).

Table 3. Schematic diagrams, cross section and photographs of prepared aerogel-enhanced textile packages

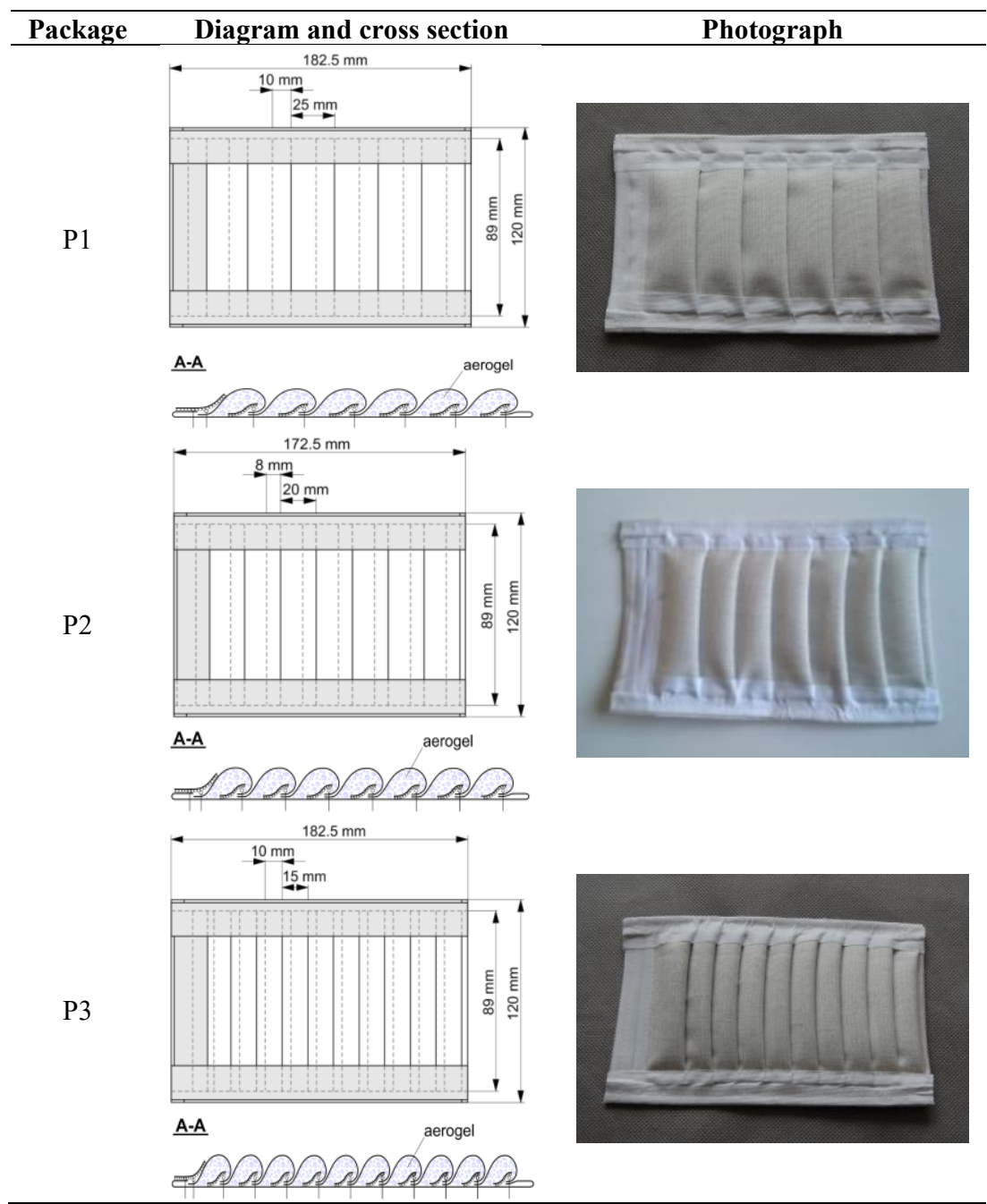


Table 4. Characteristics of aerogel-enhanced textile packages

\begin{tabular}{ccccccc}
\hline \multirow{2}{*}{ Symbol } & \multirow{2}{*}{ No. of pouches } & $\begin{array}{c}\text { Package dimensions, mm } \\
\text { Length }\end{array}$ & Width & Package thickness, mm & \multicolumn{2}{c}{ Weight, $g$} \\
Package & Aerogel \\
\hline P1a & 6 & 182.5 & 120.0 & 11.5 & 18.3 & 5.9 \\
P1b & 6 & 182.5 & 120.0 & 10.2 & 17.5 & 8.1 \\
P1c & 6 & 182.5 & 120.0 & 9.3 & 24.2 & 7.4 \\
P2a & 7 & 172.5 & 120.0 & 11.6 & 18.1 & 6.0 \\
P3a & 10 & 182.5 & 120.0 & 11.6 & 23.2 & 6.3 \\
\hline
\end{tabular}

Package P1 had three variants depending on the fabric used: an aramid fabric with polyurethane coating (designated as P1a), an aramid fabric with a Teflon membrane (P1b), and an aramid fabric with an acrylic-styrene dispersion coating (P1c). Packages P2 and P3 were made only with the aramid fabric with polyurethane coating (designated $\mathrm{P} 2 \mathrm{a}$ and $\mathrm{P} 3 \mathrm{a}$, respectively). The packages are characterized in Table 4, which provides their dimensions and weight without aerogel, as well as the weight of the aerogel filling.

The thickness of each package was measured with $0.01 \mathrm{~mm}$ resolution in 12 randomly selected locations, according to the standard EN ISO 5084:1996 [46] using a Rainbow T (Schröder Prüftechnik, Germany) thickness gauge with a $50.5 \mathrm{~mm}$ foot at a pressure of $1 \mathrm{kPa}$. The packages were weighed with 0.01 $\mathrm{g}$ resolution using a PS 1200.R2 laboratory balance (Radwag, Poland).

\section{TEST METHODS}

Prior to each test described in points 3.1-3.5, samples of aerogel packages were conditioned for $24 \mathrm{~h}$ at a constant ambient temperature of $(20 \pm 2)^{\circ} \mathrm{C}$ and relative air humidity of $(65 \pm 4) \%$.

\subsection{Resistance to radiant heat}

The experimental setup consisted of the following elements (Figure 2): radiant heat source - a heater (Technical University of Lodz, Poland), a sample holder, a calorimeter, a base for bringing the calorimeter towards or away from the heat source, and a computer with software for recording temperature changes (ATT Tarnowski company, Poland). The rectangular calorimeter was made of $99 \%$ pure copper, measured $50.0 \times$ $50.3 \times 1.6 \mathrm{~mm}$, and weighed $36.0 \mathrm{~g}$. It was curved along its longer side in an arc with a radius of $130 \mathrm{~mm}$. The samples consisted of packages prepared so that the area of aerogel pouches measured $240 \times 80 \mathrm{~mm}$. The packages were mounted in the holder and placed on the front part of the calorimeter so that the pouches faced the radiant heat source. A $0.200 \mathrm{~kg}$ weight was attached to the bottom of the samples to secure their position. Tests were conducted according to the standard EN ISO 6942:2002 [47]. The samples were exposed to a radiant heat flux of $(20.0 \pm 2.0) \mathrm{kW} / \mathrm{m}^{2}$ and the time of temperature increase by $(24.0 \pm 0.1)^{\circ} \mathrm{C}$ was recorded for the calorimeter. The tests were conducted in triplicate for reference samples (packages without aerogel), or in quintuplicate for packages with aerogel. The collected data were used to calculate the density of the heat flux passing through the samples expressed as the radiant heat transfer index $\left(\mathrm{RHTI}_{24}\right)$ according to EN ISO 11612:2015 [48], with a resolution of $0.01 \mathrm{~s}$. $\mathrm{RHTI}_{24}$ is defined as the shortest time of calorimeter temperature increase by $(24.0 \pm 0.1)^{\circ} \mathrm{C}$ from a starting temperature of around $21^{\circ} \mathrm{C}$, in seconds. The obtained $\mathrm{RHTI}_{24}$ values were used to assign radiant heat resistance performance levels to the tested packages (Table 5).

Table 5. Performance level classification based on the radiant heat transfer index ( $\left.\mathrm{RHTI}_{24}\right)$ according to EN ISO 11612:2015 [48]

\begin{tabular}{ccc}
\hline \multirow{2}{*}{ Performance level } & \multicolumn{2}{c}{ RHTI $_{\mathbf{2 4}}[\mathbf{s}]$} \\
\cline { 2 - 3 } & Min & Max \\
\hline C1 & 7.0 & $<20.0$ \\
C2 & 20.0 & $<50.0$ \\
C 3 & 50.0 & $<95.0$ \\
C4 & 95.0 & - \\
\hline
\end{tabular}

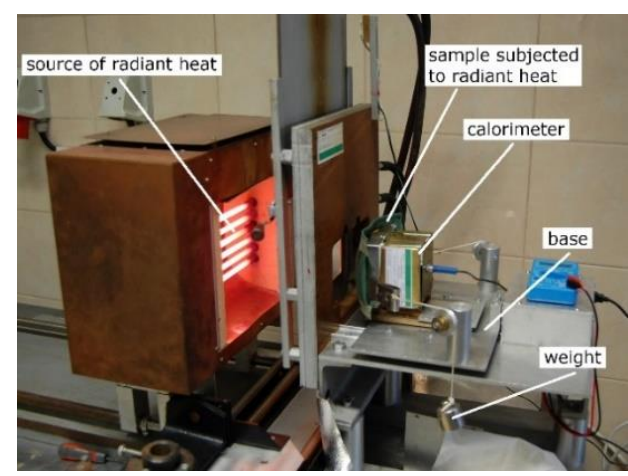

Figure 2. Experimental stand for measuring resistance to radiant heat

\subsection{Resistance to convective heat}

Resistance to convective heat was determined using an experimental setup consisting of a gas burner, a disc calorimeter, a specimen support frame, a support stand, and recording equipment (Figure 3 ). Textile package samples were exposed to a heat flux of $(80.0 \pm 2.0) \mathrm{kW} / \mathrm{m}^{2}$ generated by the gas burner. Heat transfer through the samples was measured by the calorimeter, which was placed in a horizontal position immediately under them. The calorimeter, made of $99 \%$ pure copper, had a flat surface with a diameter of $40 \mathrm{~mm}$; it was 1.6 $\mathrm{mm}$ thick and weighed $18.0 \mathrm{~g}$. Upon exposure to convective heat, the time of calorimeter temperature increase by $(24.0 \pm 0.1)^{\circ} \mathrm{C}$ was recorded with a resolution of $0.01 \mathrm{~s}$. Tests were conducted according to the standard EN ISO 9151:2016 [49] in triplicate. The heat transfer index $\left(\mathrm{HTI}_{24}\right)$ was defined as the shortest time of calorimeter temperature increase by $(24.0 \pm 0.1)^{\circ} \mathrm{C}$ and was used to assign performance levels for convective heat resistance to the tested textile packages according to the standard EN ISO 11612:2015 [48], which specifies requirements for protective clothing against heat and flame (Table 6). 


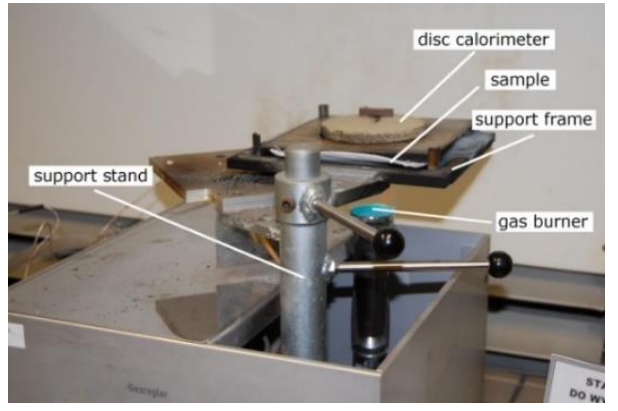

Figure 3. Experimental stand for measuring resistance to convective heat

Table 6. Performance level classification based on the heat transfer index $\left(\mathrm{HTI}_{24}\right)$ according to EN ISO 11612:2015 [48]

\begin{tabular}{ccc}
\hline \multirow{2}{*}{ Performance level } & \multicolumn{2}{c}{ HTI $_{24}[\mathbf{s}]$} \\
\cline { 2 - 3 } B1 & Min & Max \\
B2 & $\geq 4$ & $<10$ \\
B3 & $\geq 10$ & $<20$ \\
\hline
\end{tabular}

\subsection{Resistance to contact heat}

Resistance to contact heat was determined by placing a textile package sample on a calorimeter and putting it in contact with a cylinder heated to 150,200 and $250^{\circ} \mathrm{C}$ (Figure 4). The pure aluminum calorimeter had the shape of a cylindrical disc with a diameter of $25 \mathrm{~mm}$ and a thickness of 5 $\mathrm{mm}$, with a flat measurement surface. The test was conducted in accordance with the standard EN ISO 12127-1:2015 [50] to measure threshold time $\left(\mathrm{t}_{\mathrm{t}}\right)$, that is, the time from the contact of the sample with the heated cylinder to an increase of calorimeter temperature by $(10.0 \pm 0.1)^{\circ} \mathrm{C}$. The tests were conducted in triplicate with a resolution of $0.01 \mathrm{~s}$. The test results for each sample was compared with the requirements of the standard EN ISO 11612:2015 [48] to determine performance levels for protection against contact heat (see Table 7).

Table 7. Performance level classification based on threshold time $\left(t_{t}\right)$ according to EN ISO 11612:2015 [48]

\begin{tabular}{ccc}
\hline \multirow{2}{*}{ Performance level } & \multicolumn{2}{c}{$\mathbf{t}_{\mathbf{t}}[\mathbf{s}]$} \\
& Min & Max \\
\hline F1 & $\geq 5$ & $<10$ \\
F2 & $\geq 10.0$ & $<15$ \\
F3 & $\geq 15.0$ & - \\
\hline
\end{tabular}

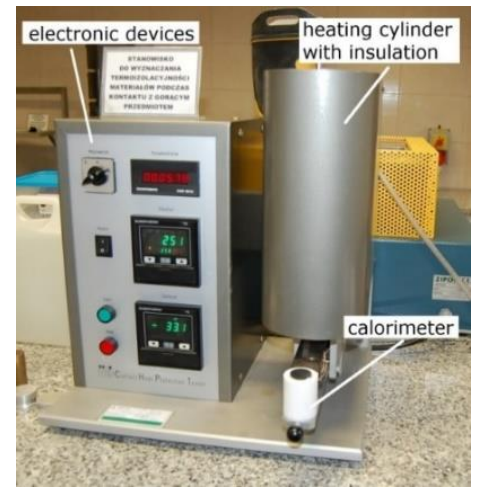

Figure 4. Experimental stand for measuring resistance to contact heat

\subsection{Water vapor resistance}

Water vapor resistance was measured in accordance with the standard EN ISO 11092:2014 [51] using a sweating guarded hot plate apparatus (ATT Władysław Tarnowski Company, Poland) consisting of a $200 \times 200 \mathrm{~mm}$ metal measuring plate with temperature and water supply control, a thermal guard with temperature control, a data control and acquisition system, and dedicated software (Figure 5). The apparatus was placed in a climatic chamber (WK 11-340/40, Weiss Umwelttechnik GmbH, Germany) which maintained constant conditions throughout the tests: a temperature of $(35 \pm 0.1)^{\circ} \mathrm{C}$ and relative humidity of $(40 \pm 3) \%$. A $300 \mathrm{~mm} \times$ $300 \mathrm{~mm}$ aerogel-enhanced textile package sample was placed on the measurement plate heated to $(35 \pm 0.1)^{\circ} \mathrm{C}$. The surface of the plate was saturated with water and covered with a vaporpermeable cellophane membrane that was impermeable to water. The airflow rate was set to $(1.0 \pm 0.05) \mathrm{m} / \mathrm{s}$. Water vapor resistance measurements were conducted at steady state with a resolution of $0.0001 \mathrm{~m}^{2} \cdot \mathrm{Pa} / \mathrm{W}$. The water vapor resistance of textile package samples $\left(\mathrm{R}_{\mathrm{ef}}\right)$ was obtained by subtracting the water vapor resistance of the air layer $\left(\mathrm{R}_{\mathrm{et} 0}\right)$ from the overall value of water vapor resistance of the textile package sample and air layer $\left(\mathrm{R}_{\mathrm{et}}\right)$. Water vapor resistance tests involved only the optimum variant of aerogel-enhanced textile packages and were conducted in triplicate.

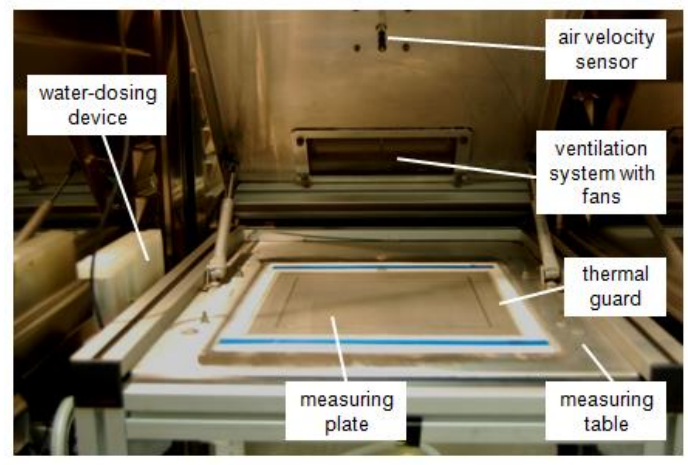

Figure 5. A view of sweating guarded hot plate apparatus for measuring water-vapour resistance

\subsection{Thermal conductivity and thermal resistance}

In order to determine the thermal conductivity and thermal resistance, the Alambeta device (Lodz University of Technology), produced by the Czech company Sensora, was used. The automatic device is mainly used to obtain dynamic and statistical assessments of thermophysical properties of materials.

The Alambeta device belongs to the group of plate measuring methods. The test procedure relies on measuring the amount of heat transmitted through the tested sample of material, located between the upper plate at $35^{\circ} \mathrm{C}$ (temperature that corresponds to the temperature of the human body) and the lower plate showing the ambient temperature. During the measurement, plates with a pressure of $200 \mathrm{~Pa}$ adhere to the sample. The main advantage of Alambeta device is short measurement time and the simultaneous obtaining of seven indicators of the tested material during one test, which characterize their thermal insulation. The Alambeta device enables the determination of following parameters: the thermal conductivity, the thermal diffusion, thermal absorption, thermal resistance, thickness, maximum and stationary heat 
flow ratio, and maximum heat flow density at the point of contact. The authors of article performed research and analysis of results of thermal conductivity and thermal resistance.

Thermal conductivity $(\lambda)$ is defined as the ability of the tested material to conduct heat. It is the amount of heat per unit area perpendicular to the direction of heat flux, per the unit temperature gradient, and also per unit time. With regard to textiles, this parameter depends mainly on the direction, in which the fibers are arranged.

Thermal resistance ( $r$ ) is defined as the resistance of material under test to heat exchanged due to the existence of temperature difference. Defined as the barrier to heat that penetrates the tested material considering the temperature difference $[33,52]$.

\subsection{Statistical analysis}

Statistical analysis was conducted to check for significant differences in protective performance between the prepared variants of aerogel-enhanced textile packages differing in terms of design and fabric type. Analysis involved radiant heat protection $\left(\mathrm{RHTI}_{24}\right)$, convective heat protection $\left(\mathrm{HTI}_{24}\right)$, and contact heat protection (threshold time, $t_{t}$ ) separately for all textile package variants. Statistical analysis was implemented in Statistica ver. 10 software at a significance level of $\mathrm{p}<0.05$. Normality of distribution was evaluated using Shapiro-Wilk's test and the significance of differences between package variants was estimated with Tukey's test.

\section{RESULTS AND DISCUSSION}

\subsection{Aerogel effects on thermal radiation}

Aerogel application significantly improved the thermal radiation resistance of all textile package variants, with the radiant heat transfer index $\left(\mathrm{RHTI}_{24}\right)$ rising by more than $100 \%$ at $\mathrm{p}=0.0002$ (Figures 6-7). The radiant heat performance of the studied packages increased from level $2\left(20 \leq \mathrm{RHTI}_{24}<50 \mathrm{~s}\right)$ to level $3\left(50 \leq \mathrm{RHTI}_{24}<95 \mathrm{~s}\right)$ or level $4\left(\mathrm{RHTI}_{24}>95 \mathrm{~s}\right)$, according to the classification presented in the standard EN ISO 11612:2015 [48].

The study also revealed a considerable effect of package design on resistance to thermal radiation, with packages containing a larger number of narrower pouches exhibiting better protective properties (Figure 6). The application of one additional pouch with a simultaneous decrease in pouch width from 25 to $20 \mathrm{~mm}$ in variant $\mathrm{P} 2 \mathrm{a}$ had only a minor effect on radiant heat resistance $\left(\mathrm{RHTI}_{24}\right.$ increased from $(83.8 \pm 6.1) \mathrm{s}$ to $(87.5 \pm 3.5) \mathrm{s}$, but the difference was not statistically significant at $p>0.05$. However, the design of package P3a, comprising the largest number of the narrowest pouches $(10 \times 15 \mathrm{~mm})$ with a greater overlap width $(10 \mathrm{~mm})$, led to a significant improvement in thermal radiation resistance. P3a exhibited an $\mathrm{RHTI}_{24}$ of $(104.9 \pm 4.6) \mathrm{s}$ at $\mathrm{p}=0.00002$, which means that it met the requirements of performance level $4\left(\mathrm{RHTI}_{24}>95 \mathrm{~s}\right)$ and was deemed the optimum package.

In contrast, the type of textile material used in the packages was not found to affect their thermal parameters (Figure 7). The three variants of package P1 (with a polyurethane-coated aramid fabric, an aramid fabric with a Teflon membrane, an aramid fabric with an acrylic-styrene dispersion coating) exhibited similar resistance to thermal radiation. Their $\mathrm{RHTI}_{24}$ values ranged from $83 \mathrm{~s}$ to $89 \mathrm{~s}$, falling within the requirements for performance level 3 according to EN ISO 11612:2015 [48]. The difference between them amounted to $6 \mathrm{~s}$ and was not statistically significant $(\mathrm{p}>0.05)$. $\mathrm{RHTI}_{24}$ measurements can be considered repeatable with standard deviation values between $0.9 \mathrm{~s}$ and $6.1 \mathrm{~s}$, representing $2.8-8.0 \%$ of the mean measured $\mathrm{RHTI}_{24}$ values (Figures 6-7).

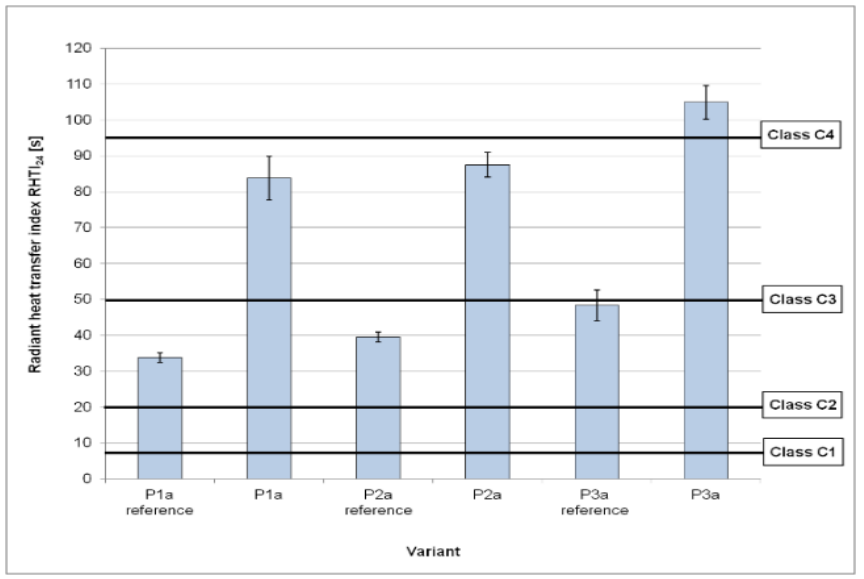

Figure 6. Radiant heat transfer index $\left(\mathrm{RHTI}_{24}\right)$ for packages with and without aerogel, differing in construction

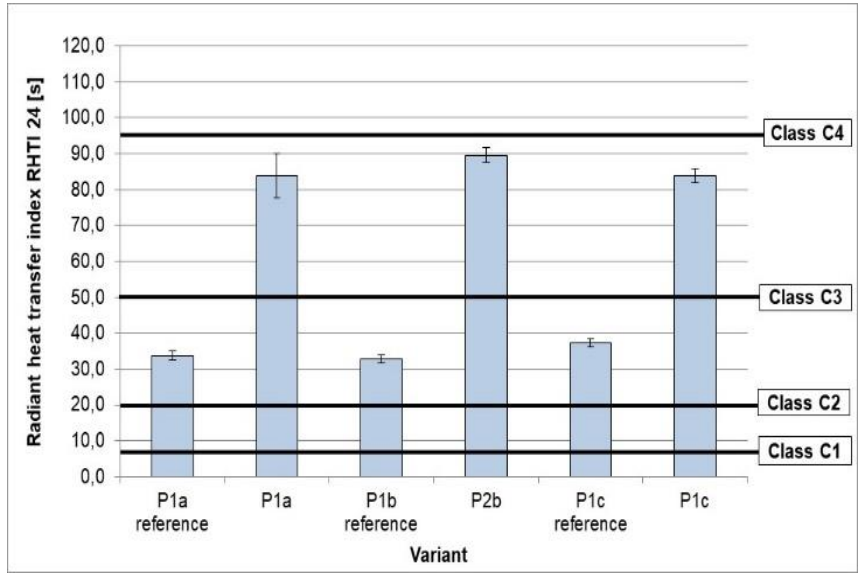

Figure 7. Radiant heat transfer index $\left(\mathrm{RHTI}_{24}\right)$ for packages with and without aerogel, differing in terms of external material

The studies of the radiant heat resistance of aerogel blankets for clothing materials were investigated by Chakraborty 2016 et al. [37]. He used for research three-layered assemblies (Nomex woven fabric, outer layer; aerogel blanket, middle layer; modacrylic/cotton fabric, inner layer). The assemblies with different fabric combinations were exposed to, higher than in our tests, heat flux of $35 \mathrm{~kW} / \mathrm{m}^{2}$. The use of an aerogel blanket in the middle layer was found to significantly improve the protective properties of the assemblies. A maximum protection time was $63.4 \mathrm{~s}$ (a $58.5 \%$ increase). The heat flux used in the presented our study was much lower $\left(20 \mathrm{~kW} / \mathrm{m}^{2}\right)$, while the obtained increase in radiant heat resistance for the optimum aerogel-enhanced textile package (P3a) exceeded $100 \mathrm{~s}$, which represents an approx. 100\% increment. This shows that the application of aerogel granules in package pouches was more effective than aerogel implementation in a nonwoven structure. This is also corroborated by the study of Miśkiewicz et al. [33]. She reported that the increase in heat transfer index for basalt fabrics with a thin silica aerogel coating exposed to the same heat flux of $20 \mathrm{~kW} / \mathrm{m}^{2}$ depended 
on an even aerogel distribution on the surface, which was difficult to achieve [33]. As a result, the obtained improvement amounted to as little as $3 \mathrm{~s}$ (only the lowest performance level was achieved). In the case of packages filled with aerogel, we had no problem with evenly applying the aerogel dispersion of a certain thickness. So it is a simpler way to apply aerogel. Similar findings were reported in our previous studies [53] concerning a textile-polymer composite produced by coating a meta-aramid fabric with a granular aerogel dispersion. The $\mathrm{RHTI}_{24}$ increased by approx. $15 \%$ and $25 \%$ for composites with coatings containing $14 \%$ and $17 \%$ wt. of aerogel. It only meant a few seconds to improve of resistance to radiant heat. Similarly to the basalt fabric with an aerogel layer, the aerogelcoated composites were classified at performance level 1 (only the lowest level).

Bhuiyan et al. [17] observed that, as expected, the radiant heat resistance of the developed aerogel-nonwoven (viscosepolyester) system increased with the increment of aerogel concentration in the nonwoven structure, but only up to a point. The implementation of $1 \mathrm{~g}$ and $2 \mathrm{~g}$ of aerogel in a nonwoven sample increased the time to pain threshold from $192 \mathrm{~s}$ to approx. $240 \mathrm{~s}$ and approx. $300 \mathrm{~s}$, respectively. The optimum level of nonwoven filling with aerogel was $3 \mathrm{~g}$ with no further increase in the time to pain threshold or second-degree burn. The findings of Bhuiyan et al. [17] are in line with the presented results for aerogel-enhanced textile packages, as a small increase in aerogel content (from $5.9 \mathrm{~g}$ to $6.3 \mathrm{~g}$ ), combined with package design modifications, led to an approx. $30 \% \mathrm{RHTI}_{24}$ increment (from $84 \mathrm{~s}$ to $105 \mathrm{~s}$ ). Such a significant improvement in resistance to radiant heat results from, similarly to the studies by Bhuiyan et al. [17] from very low thermal conductivity of aerogel, as already mentioned in the discussion of aerogel properties.

\subsection{Aerogel effects on convective heat resistance}

The application of aerogel in packages significantly improved their resistance to convective heat, with a more than $100 \%$ increase in the heat transfer index $\left(\mathrm{HTI}_{24}\right)$ recorded irrespective of the package variant (Figure 8). $\mathrm{HTI}_{24}$ values amounted to $(31.4 \pm 1.3) \mathrm{s}$ for package $\mathrm{P} 1 \mathrm{a},(46.4 \pm 3.1) \mathrm{s}$ for $\mathrm{P} 2 \mathrm{a}$ (an increment of 50\%), and (65.5 \pm 2.2 ) s for P3a (an increment of $108 \%$ ). Thus, just as in the case of radiant heat resistance, also here package P3a with ten $15 \mathrm{~mm}$ wide pouches was found to be the optimum variant. Statistical analysis showed significant differences between different package designs $(p=0.0002)$. The application of aerogel in pouches increased resistance to convective heat from performance level 2 (10 $\leq$ $\left.\mathrm{HTI}_{24}<20 \mathrm{~s}\right)$ to level $3\left(\mathrm{HTI}_{24} \geq 20 \mathrm{~s}\right)$, which is the highest rating in EN ISO 11612:2015 [48].

A comparison of different aramid fabrics (with a polyurethane coating, a Teflon membrane, and an acrylicstyrene dispersion coating) showed that the type of textile material did not affect the convective heat resistance of packages (Figure 9). The $\mathrm{HTI}_{24}$ values determined for them ranged from 31 to $45 \mathrm{~s}$, which means that all packages met the requirements of the highest performance level specified in EN ISO 11612:2015 [48]. Statistical analysis did not reveal any significant differences between the packages $(p>0.05)$. The standard deviation of $\mathrm{HTI}_{24}$ results ranged from 0.5 to $3.1 \mathrm{~s}$, amounting to $3.2-6.4 \%$ of the mean measured values.

The study conducted by $\mathrm{Na}$ et al. [40] indicated that also the addition of 1.5 or $3.0 \%$ wt. of silica aerogel to silica fabrics coated with silicone resins improved their resistance to convective heat with $\mathrm{HTI}_{24}$ increasing from approx. $9 \mathrm{~s}$ to 10.5 s (by approx. 15\%) for an aerogel content of 3\% wt. This improvement was much lower than that recorded for the aerogel-enhanced textile packages studied herein (200-250\%) due to the differences in the method of aerogel application. Nevertheless, $\mathrm{Na}$ [40] reported that fabrics containing aerogel exhibited better thermal properties than those with vermiculite, which is also known for its insulation properties. While $\mathrm{Na}[40]$ did not find significant differences in $\mathrm{HTI}_{24}$ between fabric samples containing 1.5 and $3.0 \%$ wt. of silica aerogel, the thermal performance of materials with vermiculite increased with its concentration (up to $20 \% \mathrm{wt}$.).

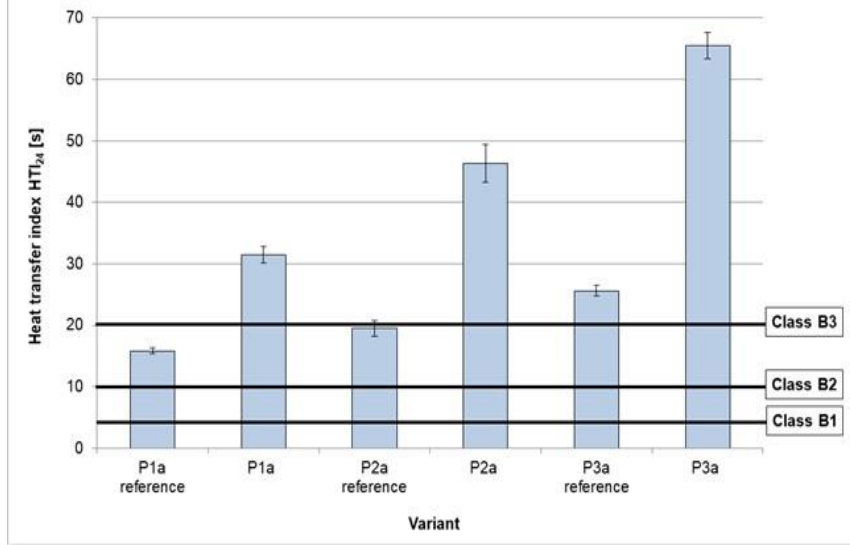

Figure 8. Heat transfer index $\left(\mathrm{HTI}_{24}\right)$ for packages with and without aerogel, differing in construction

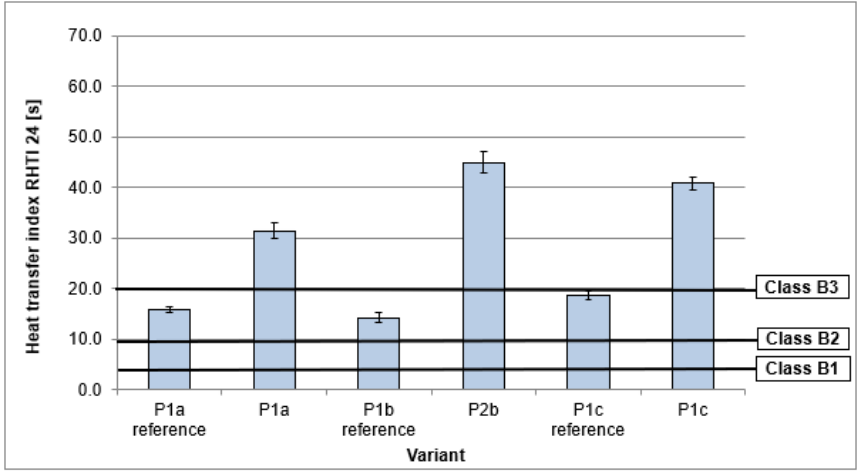

Figure 9. Heat transfer index $\left(\mathrm{HTI}_{24}\right)$ for packages with and without aerogel, differing in terms of external material

An aerogel-enhanced aramid nonwoven designed for the thermal insulation layer of firefighter clothing was tested by Jin et al. [12] in terms of convective heat resistance using the same type of copper calorimeter as the one employed in the present study for investigating textile packages. Jin et al. found that the $\mathrm{HTI}_{24}$ values of samples increased in proportion to aerogel content, from $17 \mathrm{~s}$ for an untreated sample to $21 \mathrm{~s}$ (approx. 20\%) for a laminated sample with $68.2 \%$ aerogel concentration. Jin et al. [12] also observed that the $\mathrm{HTI}_{24}$ values of laminated samples were higher than those of nonlaminated samples, which indicates that the PTFE membrane could also improve resistance to convective heat as nonlaminated samples were damaged by flame. Jin et al. [12] pointed to some problems with material homogeneity, with the main difficulty being the use of acetone as a solvent in the process of nonwoven impregnation with an aerogel dispersion. A similar problem was noted by Krzemińska et al. [53] for a 
meta-aramid fabric coated with a latex dispersion with aerogel (100-700 $\mu \mathrm{m}$ particle size) as aerogel particles tended to be crushed in the process of coating. As a result, the obtained improvement of thermal resistance properties may be lower than expected. The works of Na et al. [40] and Jin et al. [12] showed that fabric coatings lead to an approx. 15-20\% increase in thermal resistance as compared to the approx. 200$250 \%$ improvement for the aerogel-enhanced textile packages presented herein. Thus, such packages could be implemented in protective clothing to provide added safety in areas at greatest risk of injury, such as the thoracic region.

\subsection{Aerogel effects on contact heat resistance}

The present study showed that the application of aerogel in pouches led to a dramatic improvement in the resistance of textile packages to contact heat irrespective of package design and testing temperature (Figure 10). For tests at the highest temperature $250^{\circ} \mathrm{C}$, experiments demonstrated an approx. sevenfold-eightfold increase in threshold time: from $(15.2 \pm 0.7) \mathrm{s}$ to $(113.6 \pm 9.1) \mathrm{s}$ for P1a, from $(15.5 \pm 0.7) \mathrm{s}$ to $(112.8 \pm 26.7) \mathrm{s}$ for $\mathrm{P} 2 \mathrm{a}$ and from $(17.7 \pm 0.4) \mathrm{s}$ to $(139.9 \pm 4.9) \mathrm{s}$ for P3a $(p=0.0002)$. Similarly as in the case of radiant and convective heat, the best result was obtained for package $\mathrm{P} 3 \mathrm{a}$, characterized by the greatest number of pouches (10) with the smallest width $(15 \mathrm{~mm})$, but the $26 \mathrm{~s}$ difference between the tested package variants was not statistically significant $(p>0.05)$. It should be noted that all of the developed package designs met the requirements of the highest (third) performance level for contact heat resistance $\left(t_{t}>15 s\right)$ as specified in the standard EN ISO 11612:2015 [48].

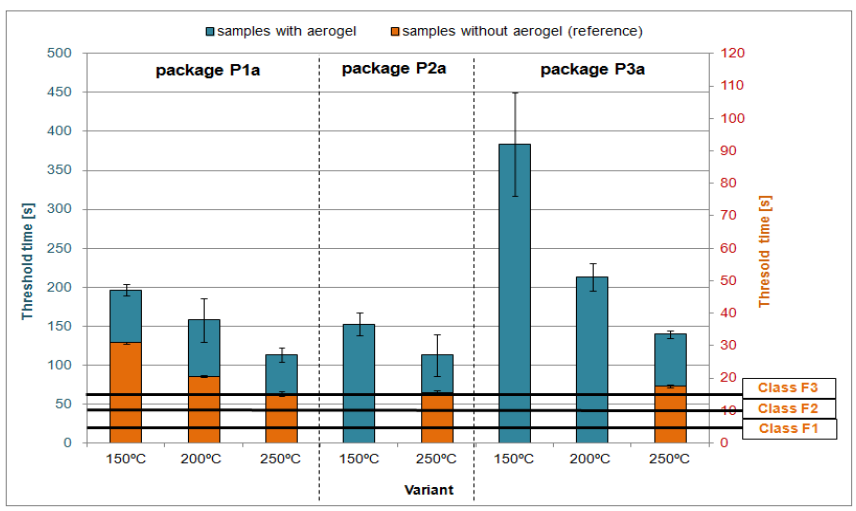

Figure 10. Threshold time $\left(\mathrm{t}_{\mathrm{t}}\right)$ for packages with and without aerogel, differing in construction and testing temperature

For all tested variants of packages with aerogel, i.e. P1a, P2a and $\mathrm{P} 3 \mathrm{a}$, the same tendency can be noticed: the threshold time decreases as the testing temperature increases (Figures 11a and $11 \mathrm{~b})$. This relationship is linear $\left(\mathrm{R}^{2}=0.9982\right.$ for $\mathrm{P} 1 \mathrm{a}$ and $\mathrm{R}^{2}=$ 0.9496 for P3a). The longest threshold time $\left(\mathrm{t}_{\mathrm{t}}\right)$ was obtained at the temperature of $150^{\circ} \mathrm{C}$, while for the $\mathrm{P} 2 \mathrm{a}$ package (with 7 pouches $)$ it was $(152.8 \pm 14.4) \mathrm{s}$ and for the P3a package (with 10 pouches) more than 2.5 times more, i.e. $(383.3 \pm 14.4)$ $\mathrm{s}$ (Figure 11a). By increasing the temperature of heating cylinder to $250^{\circ} \mathrm{C}$, in the case of $\mathrm{P} 3$ a package, the $\mathrm{t}_{\mathrm{t}}$ decreased to $(139.9 \pm 4.9)$ s, i.e. over 2.7 times compared to the $t_{t}$ determined at $150^{\circ} \mathrm{C}$. In the diagram (Figure 11a), it can also be noticed that the differences in the threshold time value for different packets (P1a, P2a, P3a) decrease with increasing temperature. At the highest testing temperature of $250^{\circ} \mathrm{C}$, the threshold time value ranges from $(15.2 \pm 0.7) \mathrm{s}$ for $\mathrm{P} 1 \mathrm{a}$ to
$(139.9 \pm 4.9)$ s for $\mathrm{P} 3 \mathrm{a}$.

By analyzing the graph of the dependence of the threshold time on the testing temperature for the Pla package (with and without aerogel) (Figure 11b), it can be concluded that the use of aerogel caused the increase of the $t_{t}$ by over $98 \mathrm{~s}\left(\right.$ at $250^{\circ} \mathrm{C}$ ) to even $166 \mathrm{~s}\left(\right.$ at $150^{\circ} \mathrm{C}$ ) in relation to the reference package. In the case of the package without the aerogel, the change of the testing temperature from 150 to $250^{\circ} \mathrm{C}$ caused a decrease in the threshold time by nearly 16 s, i.e. $50.8 \%$, (from 30.9 to $15.2 \mathrm{~s})$. In the case of P1a package with aerogel, this time decreased by as much as 84 s, i.e. $42.6 \%$ (from $197.8 \mathrm{~s}$ to 113.6 s). This may be due to from the fact that the thermal conductivity of aerogels increases with increasing temperature, which was confirmed by research conducted, among others by Morettu et al. [54].

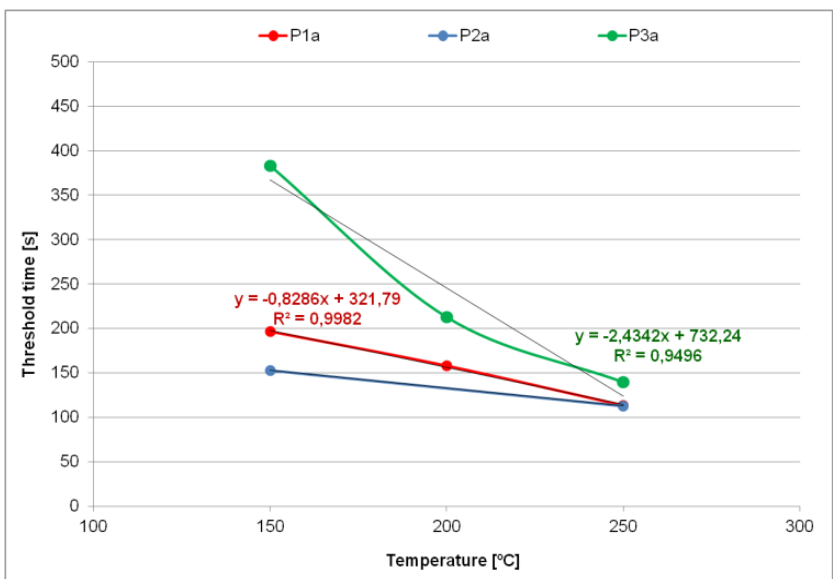

a)

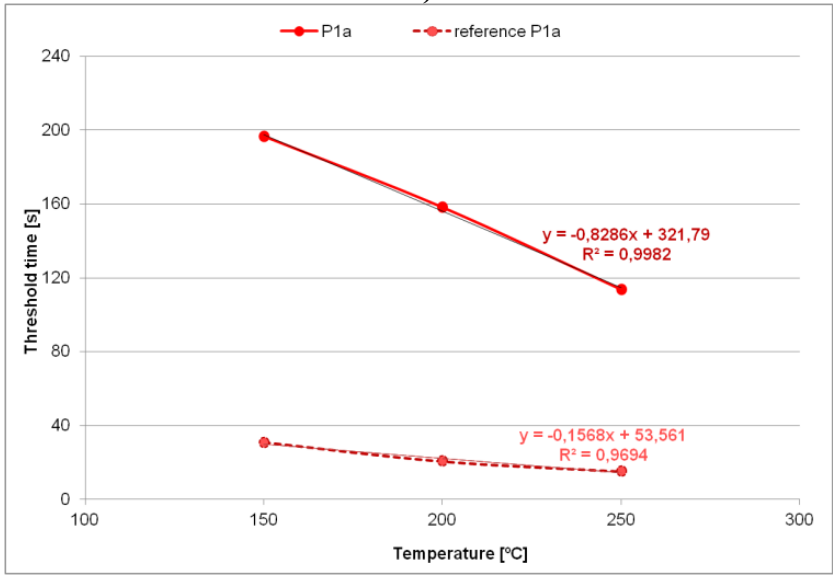

b)

Figure 11. Threshold time ( $\mathrm{t}_{\mathrm{t}}$ ) for a) packages P1a, P2a, P3a with aerogel, differing in construction and testing temperature; b) package P1a with and without aerogel differing in testing temperature

Analysis of the properties of textile packages made from different materials showed that, unlike resistance to radiant and convective heat, contact heat resistance was affected by the type of material used (Figure 12). The best result was obtained for package P1a made of an aramid fabric with a PU coating: it was $(113.6 \pm 9.1) \mathrm{s}$ as compared to $(86.4 \pm 1.9) \mathrm{s}$ for the least favorable package variant with an acrylic-styrene dispersion coating (P1b), with the $27 \mathrm{~s}$ difference being statistically significant at $p=0.0033$. The threshold times obtained for packages with all fabric variants were much longer than those specified in EN ISO 11612:2015 [48] for the highest contact heat performance level $\left(\mathrm{t}_{\mathrm{t}} \geq 15 \mathrm{~s}\right)$. Standard 
deviation values for $t_{t}$ ranged from 0.7 to $9.1 \mathrm{~s}$, which represents $4.4-8.0 \%$ of the mean measured $t_{t}$ values.

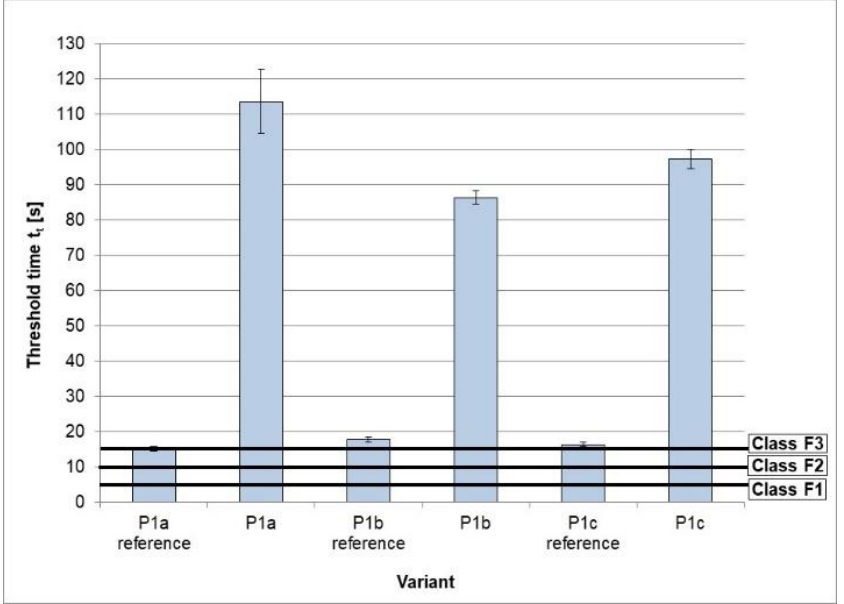

Figure 12. Threshold time $\left(t_{t}\right)$ at $250^{\circ} \mathrm{C}$ for packages with and without aerogel, differing in terms of external material

The resistance of clothing materials to contact heat was also studied by Shaid et al. [22], who analyzed those properties for textile packages with and without aerogel, similarly to the present authors. Shaid et al. compared a commercial reinforcement material used conventionally in protective clothing with an aerogel-enhanced nonwoven material, which was found to exhibit excellent compressive heat resistance. The tested materials were subjected to heat $\left(60^{\circ} \mathrm{C}\right.$ or $\left.200^{\circ} \mathrm{C}\right)$ at a compression force of $(49 \pm 0.5) \mathrm{N}$ in a special chamber. Upon contact exposure to $60^{\circ} \mathrm{C}$, the pain threshold temperature was reached within $3 \mathrm{~min}$ for the conventional reinforcement material, while the temperature behind a combination of Nomex face cloth (thermal liner) and the aerogel-containing nonwoven remained below $36^{\circ} \mathrm{C}$ even after $40 \mathrm{~min}$. When the samples were compressed on a surface heated to $200^{\circ} \mathrm{C}$, the temperature behind the conventional reinforcement material quickly rose above $70^{\circ} \mathrm{C}(30 \mathrm{~s})$ as compared to over $4 \mathrm{~min}$ for the aerogel-enhanced material. Thus, the thermal resistance of the aerogel-containing nonwoven was eight times greater than that of the standard reinforcement material and two times greater than that of the combined thermal liner and moisture barrier. The results reported by Shaid et al. [22] are similar to the present findings, indicating that the application of aerogels in protective clothing materials leads to a substantial improvement in contact heat resistance. Similarly as in the experiments conducted by Shaid et al., in the current work the use of aerogel in textile packages caused ninefold increase in threshold time (from 15.2 to $139.9 \mathrm{~s}$ for the optimum package variant).

Miśkiewicz et al. [33] conducted an interesting study on the heat resistance of basalt fabrics to contact temperatures of $100^{\circ} \mathrm{C}$ and $250^{\circ} \mathrm{C}$. At the higher temperature, which was also used in this work, Miśkiewicz et al. reported a significant difference in $t_{t}$ between basalt fabrics without and with an aerogel coating: $(4.3 \pm 0.2) \mathrm{s}$ vs $(8.8 \pm 0.8) \mathrm{s}$. At the lower cylinder temperature $\left(100^{\circ} \mathrm{C}\right)$, the $\mathrm{t}_{\mathrm{t}}$ value for the aerogelcoated fabric was approx. $27.7 \mathrm{~s}$. The research carried out by us also confirmed that the application of aerogels to the packages has a beneficial effect on the increasing protection against contact heat. As in the research conducted by Miśkiewicz et al. [33] it was noticed that the $t_{t}$ decreased with increasing testing temperature. As can be seen, the application of aerogels, whether in the form of a coating or granules incorporated in textile packages, provides very effective protection against contact heat.

\subsection{Aerogel effects on water-vapor resistance}

Water-vapor resistance is crucial for clothing materials as it determines the thermophysiological comfort of garments. High water vapor resistance impedes sweat evaporation from the skin, which may cause thermal stress in the wearer in hot and humid environments [17]. In this work, water vapor resistance tests were performed for the optimum aerogelenhanced textile package (P3a), characterized by the greatest number of pouches with the smallest width and the widest pouch overlap (Table 8).

Table 8. Water vapor resistance results

\begin{tabular}{cc}
\hline Package/Parameter & Water-vapor resistance, $\mathbf{~ m}^{\mathbf{2}} \cdot \mathbf{P a} / \mathbf{W}$ \\
\hline $\mathrm{P} 3 \mathrm{a}$ & $89.2 \pm 1.8$ \\
\hline
\end{tabular}

To the best of our knowledge, there is no published research to date on the water vapor resistance of aerogel-enhanced textile packages, but some authors have reported on fabrics and nonwovens incorporating aerogel. The cotton fabric with a polyurethane-aerogel coating developed by Bhuiyan et al. [34] exhibited a water vapor resistance of approx. 60-75 $\mathrm{m}^{2} \cdot \mathrm{Pa} / \mathrm{W}$, depending on the percentage content of aerogel in the coating. Those values are lower than those for the heat resistant package P3a by approx. 16-33\%, but it should be noted that $\mathrm{P} 3 \mathrm{a}$ is approx. 10 times thicker than the chemical protective fabrics prepared by Bhuiyan et al. $(0.77-1.28 \mathrm{~mm})$. This difference is attributable to the fact that material thickness is of lesser importance in chemical protection. Subsequent work by Bhuiyan et al. [17], which involved two-layer nonwovens with silica aerogel particles distributed between them, indicated that water vapor resistance increased with material thickness in the range of $6-9 \mathrm{~m}^{2} \cdot \mathrm{Pa} / \mathrm{W}$. As can be seen, the reported values are up to 10 times lower than those determined in the present study for package P3a. This can be explained by the fact that the nonwovens did not have any coating or sealing layer preventing the release of aerogel particles.

Venkataraman et al. [16] demonstrated a relationship between the density of aerogel-enhanced nonwovens and their water vapor resistance. Nonwovens with the highest density (79.6 and $80.4 \mathrm{~kg} / \mathrm{m}^{3}$ ) exhibited a water vapor resistance of $28-$ $29 \mathrm{~m}^{2} \cdot \mathrm{Pa} / \mathrm{W}$ as compared to $18 \mathrm{~m}^{2} \cdot \mathrm{Pa} / \mathrm{W}$ for a nonwoven with a density of $66.7 \mathrm{~kg} / \mathrm{m}^{3}$. These values were much lower than those recorded for the aerogel-enhanced package P3a in the present study. This may be attributable to the fact that, in contrast to $\mathrm{P} 3 \mathrm{a}$, those nonwovens were not bonded to any material preventing aerogel dust release, such as a membrane or a coated fabric. Coated fabrics have an unfavorable effect on water vapor resistance, but they prevent the loss of aerogel particles from the protective products.

\subsection{Fabrics effect on thermal conductivity $i$ thermal resistance}

10 measurements were performed for each fabric. Selected thermal insulation properties of tested fabrics, i.e., the thermal conductivity (Figure 13) and thermal resistance (Figure 14), are illustrated below. 


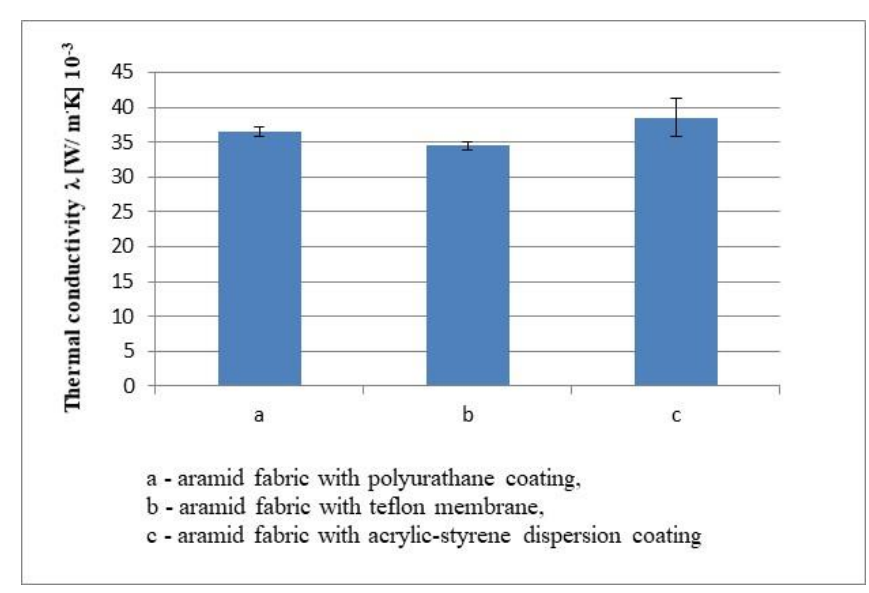

Figure 13. Relationship between thermal conductivity and the type of fabric used

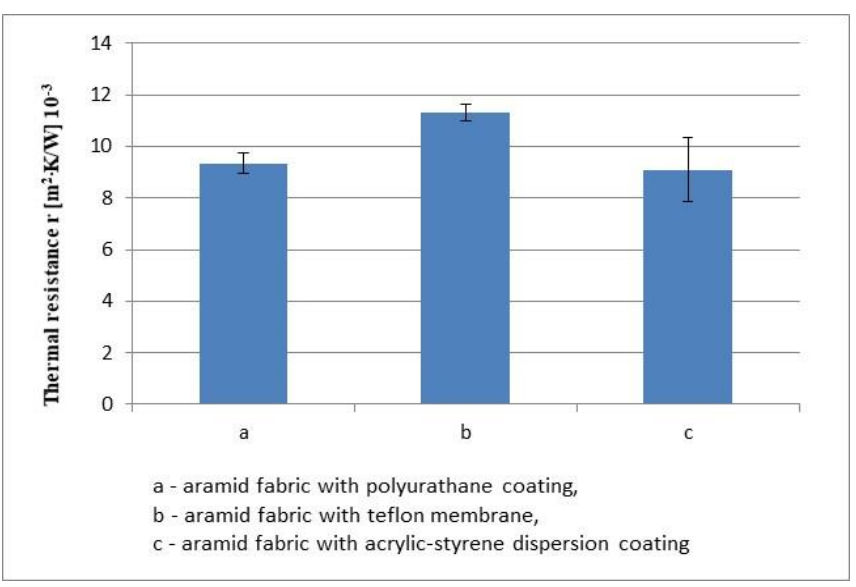

Figure 14. Relationship between thermal resistance and the type of fabric used

Thermal conductivity characterizes a textile's ability to conduct heat. Under the same conditions, much more heat will flow through the material with the higher thermal conductivity. This parameter depends on the structure and porosity of tested material. The chart shows that the highest thermal conductivity of $38.48 \times 10^{-3} \mathrm{~W} / \mathrm{m}^{-} \mathrm{K}$ was obtained for the aramid fabric with an acrylic-styrene dispersion coating, while the lowest one was for the aramid fabric with a teflon membrane - $34.46 \times 10^{-3}$ $\mathrm{W} / \mathrm{m} \cdot \mathrm{K}$. In the case of fabric with a teflon membrane, it is the membrane that is responsible for blocking the free flow of heat. In the aramid fabric with an acrylic-styrene dispersion coating, there may be pores in the fabric, because the specific thickness of the coating applied in various places may more or less clog the pores of the fabric, or there may be places, where not only the uneven distribution of the coating occurs, but also a lack of coating, which causes pores that allow the free flow of heat. It should also be remembered that the applied coating may become damaged or chipped during the use, causing the thermal conductivity coefficient to increase even more. In the case of the aramid fabric with the styrene acrylic dispersion coating, the largest dispersion of thermal conductivity values among all the tested fabrics was observed, visible in the standard deviation (error bars), which is caused by different fabric thicknesses in different fabric what is related to the uneven application of the coating.

The lower the value of thermal conductivity, the better the thermal insulation properties, so the best package in terms of thermal insulation would be obtained by combining an aramid fabric with teflon membrane and aerogel. Tests on the Alambeta device have shown that the best thermal insulation were noticed for the package of aramid fabric with a teflon membrane, characterized by the lowest thermal conductivity $\left(34.46 \times 10^{-3} \mathrm{~W} / \mathrm{m} \cdot \mathrm{K}\right)$ and aerogel, characterized according to specifications $[44,45]$ by three times lower thermal conductivity than this fabric $\left(12 \times 10^{-3} \mathrm{~W} / \mathrm{m} \cdot \mathrm{K}\right)$.

The highest value of thermal resistance was obtained for the aramid fabric with the Teflon membrane, which means that this fabric is the best barrier to the heat that penetrates through it during the test (Figure 14). This statement is justified, it results from the fact that the teflon membrane contributes to the lowest heat transfer of the fabric, which is associated with the increase in heat resistance of aramid fabric with teflon membrane. The highest value of thermal conductivity was obtained for this fabric.

\section{CONCLUSIONS}

The presented results show the considerable application potential of aerogels incorporated in textile packages for heat protective clothing. Three different package designs were developed and assessed in terms of thermal resistance. Package design was found to play a major role in achieving high performance levels in terms of protection against radiant heat, as well as convective and contact heat. The properties of packages were improved by the application of aerogel as well as by increasing the number of pouches and decreasing their width, with the best results achieved for the variant with the greatest number of pouches. The type of textile fabric mattered only in the case of contact heat experiments. Also the greatest improvement in thermal resistance was obtained in contact heat studies (an eightfold increment in test at $250^{\circ} \mathrm{C}$ ). At a lower temperature (i.e. $150^{\circ} \mathrm{C}$ ), this time was as much as (383.3 \pm 66.4$) \mathrm{s}$ and was over 2.7 times higher than at $250^{\circ} \mathrm{C}$. Tests on the Alambeta device have shown that in order to obtain the best thermal insulation properties from among the three fabrics selected for testing, a package should be prepared from an aramid fabric with a teflon membrane, characterized by the lowest thermal conductivity and aerogel, characterized by three times lower thermal conductivity than this fabric.

The findings indicate that the application of silica aerogelenhanced textile packages as inserts in protective clothing may significantly improve its resistance to radiant, convective and contact heat. The resulting superior performance levels offer greater worker protection, affording more time to safely move out of harm's way. Further research should be conducted to determine the optimum shape and size of packages for individual user needs.

\section{SOURCE OF SUPPORT}

The present publication is based on the results of Phase IV of the National Program "Safety and working conditions improvement" funded in the years 2017-2019 in the area of research and development work by the Ministry of Science and Higher Education / The National Centre for Research and Development, Poland. The Program's coordinator is the Central Institute for Labour Protection - National Research Institute, Warsaw, Poland. 


\section{ACKNOWLEDGEMENTS}

The authors thank the company P.P.H.U. Bochemia, Poland for help with coating aramid fabric with an acrylic-styrene dispersion.

The authors are also grateful to Optex S.A., Poland for assistance with coating aramid fabric with a teflon membrane.

\section{REFERENCES}

[1] McNaught, A.D., Wilkinson, A. (1997). IUPAC. Compendium of chemical technology, (the "Gold Book"). Blackwell Scientific Publications, Oxford. https://doi.org/10.1351/goldbook

[2] Gurav, J.L., Jung, I.K., Park, H.H., Kang, E.S., Nadargi, D.Y. (2010). Silica aerogel: Synthesis and applications. Journal of Nanomaterials, 2010. https://doi.org/10.1155/2010/409310

[3] Li, M., Jiang, H., Xu, D., Hai, O., Zheng, W. (2016). Low density and hydrophobic silica aerogels dried under ambient pressure using a new co-precursor method. Journal of Non-Crystalline Solids, 452: 187-193. https://doi.org/10.1016/j.jnoncrysol.2016.09.001

[4] Patel, R.P., Purohit, N.S., Suthar, A.J. (2009). An overview of silica aerogel. International Journal of ChemTech Research, 1(4): 1052-1057.

[5] Liao, J.J., Gao, P.Z., Xu, L., Feng, J. (2018). A study of morphological properties of $\mathrm{SiO}_{2}$ aerogels obtained at different temperatures. Journal of Advanced Ceramics, 7(4): 307-316. https://doi.org/10.1007/s40145-0180280-6

[6] Bheekhun, N., Talib, A., Rahim, A., Hassan, M.R. (2013). Aerogels in aerospace: An overview. Advances in Materials Science and Engineering, 2013. https://doi.org/10.1155/2013/406065

[7] Thapliyal, P.C., Singh, K. (2014). Aerogels as promising thermal insulating materials: An overview. J. Mater, 2014(10). https://doi.org/10.1155/2014/127049

[8] Liu, Z., Ding, Y., Wang, F., Deng, Z. (2016). Thermal insulation material based on $\mathrm{SiO}_{2}$ aerogel. Construction and Building Materials, 122: 548-555. https://doi.org/10.1016/j.conbuildmat.2016.06.096

[9] Saio, C., Nocentini, K., Tagliafico L.A., Biwole, P.H., Achard, P. (2017). Application of advanced insulating materials in historical buildings. International Journal of Heat and Technology, 35(1): S345-S352. https://doi.org/10.18280/ijht.35Sp0147

[10] Peng, L., Su, B., Yu, A., Jiang, X. (2019). Review of clothing for thermal management with advanced materials. Cellulose, 26: 6415-6448 https://doi.org/10.1007/s10570-019-02534-6

[11] Anderson, A.M., Carroll, M.K. (2011). Hydrophobic silica aerogels: Review of synthesis, properties and applications. In: Aegerter, M.A., Leventis, N., Koebel, M.M. (eds). Aerogels Handbook. Advances in Sol-Gel Derived Materials and Technologies. Springer, New York.

[12] Jin, L., Hong, K., Yoon, K. (2013). Effect of aerogel on thermal protective performance of firefighter clothing. Journal of Fiber Bioengineering and Informatics, 6(3): 315-324. https://doi.org/10.3993/jfbi09201309

[13] Shaid, A, Fergusson, M, Wang, L. (2014). Thermophysiological comfort analysis of aerogel nanoparticle incorporated fabric for fire fighter's protective clothing. Chemical and Materials Engineering, 2(2): 37-43. https://doi.org/10.13189/cme.2014.020203

[14] Shaid, A, Wang, L, Padhye, R. (2016). The thermal protection and comfort properties of aerogel and PCMcoated fabric for firefighter garment. Journal of Industrial Textiles, 45(4): 611-625. https://doi.org/10.1177/1528083715610296

[15] Jiang, Y., Zhang, L., Xu, H., Zhong, Y., Mao, Z. (2017). Preparation and characterization of thermal protective aluminum hydroxide aerogel/PSA fabric composites. Journal of Sol-Gel Science and Technology, 82: 370-379. https://doi.org/10.1007/s10971-017-4323-1

[16] Venkataraman, M., Mishra, R., Militky, J., Kremenakova, D., Petru, M. (2019). Aerogel based high performance thermal insulation materials. IOP Conference Series: Materials Science and Engineering, 553: 012043. https://doi.org/10.1088/1757-899X/553/1/012043

[17] Rahman Bhuiyan, M.A., Wang, L., Shaid, A., Jahan, I., Shanks, R.A. (2020). Silica aerogel-integrated nonwoven protective fabrics for chemical and thermal protection and thermophysiological wear comfort. Journal of Materials $\quad$ Science, 5(6): 2405-2418. https://doi.org/10.1007/s10853-019-04203-2

[18] Udayraj, Talukdar, P., Das, A., Alagirusamy, R. (2016). Heat and mass transfer through thermal protective clothing - A review. International Journal of Thermal Science, 106: 32-56. https://doi.org/10.1016/j.ijthermalsci.2016.03.006

[19] Lou, J., Wang, H. (2018). Preparation, thermal insulation and flame retardance of cellulose nanocrystal aerogel modified by $\mathrm{TiO}_{2}$. International Journal of Heat and Technology, 36: 614-618. https://doi.org/10.18280/ijht.360226

[20] Qi, Z., Huang, D., He, S., Yang, H., Hu, Y., Li, L., Zhang, H. (2013). Thermal protective performance of aerogel embedded firefighter's protective clothing. Journal of Engineered Fibers and Fabrics, 8(2): 134-139. https://doi.org/10.1177/155892501300800216

[21] Huang, D., Guo, C.N. (2017). Thermal protective performance of silica aerogel felt bedded firefighters' protective clothing under fire conditions. Materials Science, 23(4): 335-341. http://dx.doi.org/10.5755/j01.ms.23.4.16680

[22] Shaid, A., Wang, L., Padhye, R., Rahman Bhuyian, M.A. (2018). Aerogel nonwoven as reinforcement and batting material for firefighter's protective clothing: A comparative study. Journal of Sol-Gel Science and Technology, 87: 95-104. https://doi.org/10.1007/s10971018-4689-8

[23] Kim, C.Y., Lee, J.K., Kim, B.I. (2008). Synthesis and pore analysis of aerogel-glass fiber composites by ambient drying method. Colloids and Surfaces A: Physicochemical and Engineering Aspects, 313-314: 179-182. https://doi.org/10.1016/j.colsurfa.2007.04.090

[24] Iswar, S., Griffa, M., Kaufmann, R., Beltran, M., Huber, L., Brunner, S., Lattuada, M., Koebel, M.M., Malfait, W.J. (2019). Effect of aging on thermal conductivity of fiber-reinforced aerogel composites: An X-ray tomography study. Microporous and Mesoporous Materials, 278: 289-296. https://doi.org/10.1016/j.micromeso.2018.12.006

[25] Shams-Ghahfarokhi, F., Khoddami, A., MazroueiSebdani, Z., Rahmatinejad, J., Mohammadi, H. (2019). 
A new technique to prepare a hydrophobic and thermal insulating polyester woven fabric using electro-spraying of nano-porous silica powder. Surface and Coating Technology, 366:

97-105. https://doi.org/10.1016/j.surfcoat.2019.03.025

[26] Shaid, A., Wang, L., Padhye, R. (2015). The thermal protection and comfort properties of aerogel and PCMcoated fabric for firefighter garment. Journal of Industrial Textile, 45(4):

611-625. https://doi.org/10.1177/1528083715610296

[27] Linhares, T., Pessoa de Amorim, M.T., Durães, L. (2019). Silica aerogel composites with embedded fibres: A review on their preparation, properties and applications. Journal of Materials Chemistry A, 7(40): 22768-22802. https://doi.org/10.1039/C9TA04811A

[28] Mazraeh-shahi, Z.T., Shoushtari, A.M., Bahramian, A.R. et al. (2014). Synthesis, structure and thermal protective behavior of silica aerogel/PET nonwoven fiber composite. Fibers and Polymers, 15: 2154-2159. https://doi.org/10.1007/s12221-014-2154-z

[29] Prevolnik, V., Zrim, P.K., Rijavec, T. (2014). Textile technological properties of laminated silica aerogel blanket. Contemporary Materials, V-1: 117-123. https://doi.org/10.7251/cm.v1i5.1507

[30] Ahmed, F., Ulker, Z., Erkey, C. (2018). A novel composite of alginate aerogel with PET nonwoven with enhanced thermal resistance. Journal of Non-Crystalline Solids, 491: 7-13. http://doi.org/10.1016/j.jnoncrysol.2018.03.023

[31] Jabbari, M., Akesson, D., Skrifvars, M., Taherzadeh, M.J. (2015). Novel lightweight and highly thermal insulative silica aerogel-doped poly(vinyl chloride)-coated fabric composite. Journal of Reinforced Plastics and Composites, $\quad 34(19)$ : 1581-1592. https://doi.org/10.1177/0731684415578306

[32] Venkataraman, M., Mishra, R., Wiener, J., Štěpánková, M., Arumugam, V.K., Militky, J. (2015). Effect of laser irradiation on kevlar fabric treated with nanoporous aerogel.

[33] Miśkiewicz, P., Frydrych, I., Tokarska, M. (2020). Study on the use of Aerogel on the Surface of Basalt Fabric. Autex Research Journal, 20(2): 168-177. https://doi.org/10.2478/aut-2019-0054

[34] Bhuiyan, M.R., Wang, L., Shaid, A., Shanks, R.A., Ding, J. (2019). Polyurethane-aerogel incorporated coating on cotton fabric for chemical protection. Progress in Organic Coatings, 131: 100-110 https://doi.org/10.1016/j.porgcoat.2019.01.041

[35] Sindall, D., Gojny, F., Kim, H.Y. (2013). Patent US8507071B1, Sheet insulator with improved resistance to heat transfer by conduction, convection and radiation. https://patents.google.com/patent/US8507071B1/en.

[36] Seth, J., Feisel, B.C., Sharma, N., Tan, L.S., Tiefenbruck, G.F., Wu, J.S. (2014). U.S. Patent No. 8,734,931. Washington, DC: U.S. Patent and Trademark Office. https://patents.google.com/patent/US8734931B2/en.

[37] Chakraborty, S., Pisal, A.A., Kothari, V.K., Venkateswara Rao, A. (2016). Synthesis and characterization of fibre reinforced silica aerogel blankets for thermal protection. Advances in Materials Science and Engineering, 2016 https://doi.org/10.1155/2016/2495623

[38] Chakraborty, S., Venkateswara, Rao, A., Kothari, V.K., Pisal, A.A. (2019). Radiant heat protective performance of clothing assemblies with flexible aerogel-Nomex nonwoven composite as thermal insulation. Indian Journal of Fibre \& Textile Research, 44: 396-403.

[39] Li, C., Cheng, X., Li, Z., Pan, Y., Huang, Y., Gong, L. (2017). Mechanical, thermal and flammability properties of glass fiber film/silica aerogel composites. Journal of Non-Crystalline Solids, 457: 52-59. https://doi.org/10.1016/j.jnoncrysol.2016.11.017

[40] Na, H.J., Bae, J.H., An, S.K. (2011). Fireproofing performance of silica fabrics coated with silicone resin formulations. Textile Science and Engineering, 48(4): 258-264.

[41] ISO 9151:2007 Protective clothing against heat and flame. Determination of heat transmission on exposure to flame.

[42] Li, Z., Gong, L., Cheng, X., He, S., Li, C., Zhang, H. (2016). Flexible silica aerogel composites strengthened with aramid fibers and their thermal behavior. Materials \& Design, 39 99-355. https://doi.org/10.1016/j.matdes.2016.03.063

[43] EN ISO 12127-1: 2015 Clothing to protect against heat and flame. Determination of contact heat transmission through clothing or constituent materials - Part 1: Contact heat produced by heating cylinder.

[44] Greszta, A., Krzemińska, S., Okrasa, M. (2019). Influence of aging factors on the properties of aerogels with different degree of granulation. Fibres \& Textiles in Eastern $\quad$ Europe, $\quad 4:$ 50-58. https://doi.org/10.5604/01.3001.0013.1386

[45] Cabot Data Sheet. Enova Aerogel IC 3100. http://www.cabotcorp.com/solutions/productsplus/aerogel, accessed on March 1, 2018.

[46] EN ISO 5084:1996 Textiles. Determination of thickness of textiles and textile products.

[47] EN ISO 6942:2002 Protective clothing. Protection against heat and fire. Method of test: Evaluation of materials and material assemblies when exposed to a source of radiant heat.

[48] EN ISO 11612:2015 Protective clothing. Clothing to protect against heat and flame. Minimum performance requirements.

[49] EN ISO 9151:2016 Protective clothing against heat and flame. Determination of heat transmission on exposure to flame.

[50] EN ISO 12127-1:2015 Clothing for protection against heat and flame. Determination of contact heat transmission through protective clothing or constituent materials. Part 1: Contact heat produced by heating cylinder.

[51] EN ISO 11092: 2014 Textiles. Physiological effects. Measurement of thermal and water vapour resistance under steady-state conditions (sweating guarded-hotplate test).

[52] Miśkiewicz, P., Frydrych, I., Pawlak, W. (2019). The influence of basalt fabrics modifications on their resistance to contact heat and comfort properties. International Journal of Clothing Science and Technology, 31(6): 874-886. https://doi.org/10.1108/IJCST-11-2018-0147

[53] Krzemińska, S., Cieślak, M., Kamińska, I., Nejman, A. (2020). Application of Silica Aerogel in Composites Protecting Against Thermal Radiation. Clinical Chemistry and Laboratory Medicine (CCLM), 1(aheadof-print). https://doi.org/10.2478/aut-2020-0008 
[54] Moretti, E., Merli, F., Cuce, E., Buratti, C. (2017). Thermal and acoustic properties of aerogels: Preliminary investigation of the influence of granule size. Energy Procedia, 111:

https://doi.org/10.1016/j.egypro.2017.03.209
NOMENCLATURE

RHTI $_{24}$ radiant heat transfer index - time to increase of calorimeter temperature by $(24.0 \pm 0.1)^{\circ} \mathrm{C}$ in radiant heat tests, $s$

$\mathrm{HTI}_{24}$ heat transfer index - time to increase of calorimeter temperature by $(24.0 \pm 0.1)^{\circ} \mathrm{C}$ in convective heat tests, $s$

$t_{t}$ threshold time-time to increase of calorimeter temperature by $(10.0 \pm 0.1)^{\circ} \mathrm{C}$ in contact heat tests, s

$\mathrm{R}_{\mathrm{ef}} \quad$ water vapor resistance, $\mathrm{m}^{2} \cdot \mathrm{Pa} / \mathrm{W}$ 